\title{
Ciência, Tecnologia e Sociedade na contemporaneidade: implicações educacionais tramadas ao pós-estruturalismo
}

Carla Gonçalves Rodrigues

\section{Resumo}

No intuito de colaborar com a investigação científica na perspectiva Ciência, Tecnologia e Sociedade (CTS), desenvolve-se a temática utilizando como referência teorias pós-estruturalistas. Assim, por meio dos conceitos de Ciência menor (DELEUZE e GUATTARI, 2012), Tecnologias do eu (FOUCAULT, 2008) e Sociedade disciplinar e de controle (FOUCAULT, 1987; DELEUZE, 1992) realiza-se variação no arranjo conceitual, favorecendo pensá-la de outros modos, nesta contemporaneidade. Aposta-se em um pensamento científico que desenvolva a produção de novos sentidos para a Educação, envolvendo uma prática filosófica. Nessa perspectiva, os conceitos aqui reunidos, realçam os conhecimentos agregados ao mundo, no afastamento de ideologias e preconceitos oriundos da Modernidade, pois prioriza a realidade social nos dias de hoje. Nesta pesquisa bibliográfica, a Educação CTS é atravessada pela imanência, reunindo procedimentos que decorrem do vivido, que não buscam respostas e verdades, mas problemas derivados e engendramentos com outros campos dos saberes, aproximando-se do escopo da teoria aqui desenvolvida.

Palavras-chave: Educação, Ciência, Tecnologia e Sociedade (CTS), Filosofias da diferença.

\section{Abstract \\ Current Science, Technology and Society: educational implications attached to post-structuralism}

In order to collaborate with scientific research in the Science, Technology and Society (STS) perspective, it develops the thematic using as reference poststructuralists theories. Thus, through the concepts of minor Science (DELEUZE and GUATTARI, 2012), Technologies of the self (FOUCAULT, 2008), disciplinary Society and Society of control (FOUCAULT, 1987; DELEUZE, 1992) we perform variations in the conceptual arrangement, favoring the thinking in other ways, on this contemporaneity. We bet on a scientific thought that develops the production of new meanings for Education, involving a philosophical practice. In this perspective, the concepts here gathered, enhance the knowledges aggregated to the world, in the removal of ideologies and prejudices that arise from Modernity, because prioritizes social reality present on these days. In this bibliographical research, the CTS Education is cross by immanence, gathering procedures that arise from the lived, that do not seek answers and truths, but problems derived and engendering with other fields of knowledge, approaching of the theory here developed.

Keywords: Education, Science, Technology and Society (STS), Philosophies

DOI: Em andamento. 
of the difference.

\section{Introdução}

Na Sociedade contemporânea há necessidade de um olhar diferenciado para a Educação das Ciências, pois, a evolução tecnológica e o avanço científico requerem e exigem indivíduos com habilidades inerentes a esse campo, como a criticidade e o desenvolvimento constante. Em diversas disciplinas, tais como Física, Química e Biologia, essas competências não são propícias a uma Ciência apresentada de forma tradicional, compartimentada e distante da realidade dos educandos, já que dificulta os processos de ensino e aprendizagem, distanciando teoria e prática. Desse modo, prioriza-se um processo que conjugue diferentes perspectivas do conhecimento, a realidade dos alunos, a produção científica, também, uma formação de professores que trame e desenvolva temáticas sociais atuais com educacionais, possibilitando efetivas imersões nas comunidades em que se inserem as práticas escolares.

Nessa direção, surgiu no século XX, principalmente nos países capitalistas, um movimento de âmbito internacional denominado CTS que busca o desenvolvimento crítico do uso da Ciência e da Tecnologia e seus efeitos à Sociedade. Esse movimento passou a ser item de debate político no cenário mundial, tendo como um dos objetivos alterar o ponto de vista e decisões em relação à Ciência e Tecnologia, a partir de discussões realizadas de forma mais democrática e com maior participação da Sociedade. A utilização dessa perspectiva, de acordo com Linsingen (2007), está cada vez mais presente em estreita associação com a percepção das atividades tecnocientíficas, de caráter investigativo, envolvendo sustentabilidade e questões ambientais, bem como a discussão e definição de políticas públicas.

No campo educacional e do ensino das Ciências, essa temática passou a ser abordada no Brasil no início dos anos 80. Nessa época, o processo de consolidação do campo CTS em países da América Latina emergiu da reação ao modelo hegemônico de percepção das relações sociais da Ciência como neutra e fonte de verdade; da Tecnologia, enquanto ferramentas de uso operacional (LINSINGEN, 2007). Propôs um pensamento crítico, baseado principalmente em Paulo Freire (1967), tendo impacto em distintos campos do saber e nas políticas públicas, com significativa filiação a propostas de currículos e estudos na área da Educação (ABREU, 2001; ANDRADE, CARVALHO, 2002).

A teoria crítica, alicerce da CTS, busca analisar o desenvolvimento, progresso sociopolítico e econômico que compõe a Sociedade, visando à transformação de uma realidade opressora para uma mais justa e igualitária. Essas considerações são pensadas a partir de um modelo social em que a ascensão do capitalismo ditava modos de ser e fazer, tais como as mercadorias e informações que a população pode acessar.

32 DOI: Em andamento.

R. Bras. de Ensino de C\&T 
Contudo, essa Sociedade também tem se caracterizado por mudanças na forma de interpretar o mundo. 0 modo atual de vida vem gerando profundas indagações acerca dos modelos econômicos e sociais que são construídos tradicionalmente. As verdades científicas, a fragmentação do conhecimento, a racionalidade, a democracia, são questionadas e, até mesmo, o sentido do termo cidadania cunhado por Freire (1967). Por ora, o presente passa a ser marcado pelo fim dos padrões e estabilidade, fazendo surgir o tempo da indefinição (BAUMAN, 2008). Transformações tecnológicas significativas e rápidas têm sido presenciadas, como exemplo as redes sociais e a presença massiva de aparelhos celulares e computadores. Não há maiores dúvidas que tais variações afetam a cultura, modificando os modos de pensar e se comunicar nesta contemporaneidade.

Por isso, a temática aqui desenvolvida (CTS) se estende cronologicamente, sobretudo no Brasil, ao que se passa nos dias de hoje buscando amparo nas teorias Pós-modernas ou, nesse caso, Pós-estruturalistas (SILVA, 1996). Interessada pela diversidade, pluralidade e singularidade, ao contrário de uma filosofia baseada numa ideia universal e numa totalidade que contém partes isoladas. Caracterizada pela interdisciplinaridade e por novos modos de perceber o que é sujeito e o que é objeto, entende que as ciências estão sempre se transformando e se relacionando e, por isso, tanto o sujeito quanto o objeto do conhecimento são construções - ou criações. Ao adotar tal perspectiva teórica, as concepções de Ciência, Tecnologia e Sociedade são movimentadas, com vistas a uma adequação da exploração da CTS tramada ao que acontece atualmente na Educação.

Com menos força acredita na suposta autonomia de um sujeito racional, livre, autônomo, centrado e soberano, elementos que a Educação prioriza, ainda sustentada nos princípios da Modernidade. Coloca em constate dúvida as afirmações, elucidações universais, totalidades, completudes ou plenitudes (SILVA, 1996). Aqui, não interessa dizer a respeito do que está posto, subjugando e valorando negativamente os investimentos realizados até então, mas, isto sim, movimentar a CTS desenvolvendo os atravessamentos que a concepção pós-estruturalista fomenta.

É fato: a teoria Pós-estruturalista coloca em cheque a própria construção do conhecimento científico, dos métodos, técnicas, da posição em relação a outras áreas e a eficácia na Sociedade. Em vista disso, implica em evidenciar a posição do pesquisador, compromissos, contextos e contingências, estando a Ciência no próprio questionamento enquanto lugar da verdade. Nesse processo o currículo e a Educação tornam-se objetos de problematização para esse pensamento, destacando o caráter, por vezes, artificial das afirmações curriculares, saberes educacionais e conhecimentos considerados legítimos (SILVA, 1996).

Objetivando colaborar com a produção científica acerca da perspectiva CTS, investiga-se a temática utilizando a teoria Pós-estruturalista, entendendo que esse movimento se adequa, cronologicamente, ao surgimento e estabelecimento dessa perspectiva nos espaços educacionais. Por meio dos conceitos de Ciência menor (DELEUZE; GUATTARI, 2012), Tecnologias do eu

DOI: Em andamento. 
(FOUCAULT, 2008), Sociedade disciplinar e controle (FOUCAULT, 1987; DELEUZE, 1992) percorrese a CTS na Educação, com atravessamentos que permitam pensá-la de outros modos.

\section{Concepções de Ciência no pós-estruturalismo}

Na esteira do pensamento pós-estruturalista coloca-se em "suspenção" o entendimento daquilo que é considerado científico, nas verdades que contaminam o presente e desfrutam de uma aceitação social. Deleuze e Guattari (2012) pensam a Ciência maior ou régia com o seu poder a partir de teoremas inquestionáveis, buscando aprisionar os movimentos heterogêneos para subvertê-los em conceitos, categorias. A tendência do conhecimento científico é ser conduzido a partir de uma via única, de algo já instituído, ancorado em regras moldadas e organizações, com formas imutáveis que sustentam as explicações. Tal qual a rotulação de científico é dada a prática CTS de Andrade e Carvalho (2002), relacionando a produção de etanol à preservação ambiental, pois está publicada, no formato de artigo, na revista Ciência e Educação, que possui esse status.

Esta prática ocorre a partir de uma Tecnologia nacional, que por usar da cana de açúcar para produção de um combustível renovável, é certificado como sustentável, preservando a natureza. Essa preferência é pelo fato de o etanol não produzir dióxido de enxofre quando é queimado, ao contrário da gasolina que polui a atmosfera. Entretanto, nesse exercício escolar relatada por Andrade e Carvalho (2002), não há ressalvas quanto a essa fabricação, que produz diversas problemáticas, tais como, o desmatamento gerado pela monocultura da cana, a condição social e trabalhista da mão de obra empregada e o primitivo processo de colheita que obriga a queima da matéria-prima, liberando gases poluentes na atmosfera. Em uma relação com a Ciência maior, o fato de essa experiência utilizar um método, aparatos tecnológicos, estar sendo empregada na Escola e publicada em uma revista garantem um caráter científico, onde verdades e conceitos legitimadores são postos a funcionar.

Em contraponto a esse entendimento a Ciência menor ou nômade se posiciona a margem das técnicas e do sentido legalizado estabelecido pela História. Rejeita a busca de constantes e leis, a partir de variáveis, adotando como procedimento colocá-las em mutação contínua, captando singularidades da matéria e dos micromovimentos. Menos interessa a sua legitimação, por meio do método científico, mas, sim, como a reunião de saberes opera determinados conceitos resultando em uma prática efetivamente ligada a Sociedade, na tentativa de beneficiála.

Como exemplo de aplicação de uma Ciência menor, cita-se a prática pedagógica, realizada no ensino fundamental, por meio de temas sociocientíficos (MUNDIM; SANTOS, 2012). Os resultados da pesquisa que foi realizada indicam que essa abordagem propicia aos alunos relacionarem conhecimento científico com situações de sua vivência, explorando as relações CTS. Sem a preocupação de conceitos e métodos, os autores utilizaram os saberes dos estudantes 
agregados às aplicações sociais para promover os processos de ensino e aprendizagem, os exercícios tangenciaram os livros, conteúdos e as regras previamente definidas e colocaram em movimento uma Ciência aqui dita menor, tramada à contemporaneidade.

O conceito de Ciência maior parte das hipóteses advindas do método científico, que trata o objeto de estudo isoladamente e fragmentado tentando compreender e fazer a pesquisa na ordem do significado. Possui anseios de organização e classificação, dividindo amostras em mais ou menos importantes, simples ou complexas, erguendo, assim, teorias totalizantes e axiomáticas. Sustentadas nesse meio de cultivo, optam por definir e concretizar os conceitos estudados, formam um modelo único, por conseguinte, sufocam outros contornos do conhecimento, os quais não se baseiam em suas epistemologias e metodologias. Exemplificando, cita-se a construção de práticas didático-pedagógicas com formação CTS de Tenreiro-Vieira e Vieira (2005) que objetiva atingir uma meta científica, na qual os alunos possam ter uma base de conhecimentos, bem como capacidades de pensamento que lhes permitam continuar a aprender, a realizar-se no campo profissional e a lidar eficazmente com preocupações sociais.

Nessa proposta, visualizam-se características de uma Ciência maior, a partir da oferta do que pensar, de um método a ser seguido e de práticas que contextualizam a atuação no mercado de trabalho, sem, no entanto, oportunizar outros desdobramentos dos conteúdos. Quanto menor o número de pessoas interessadas no próprio pensamento, deixando de agir por si, agregando menor valor para suas inquietações, mais a Sociedade será como quer o Estado, universalizando suas intenções. Este invoca para si um rótulo de organização racional de uma comunidade, recebendo, dos próprios indivíduos, a noção de via única e totalitária, que rejeita outras explicações para as problemáticas atuais. Ao contrário, o pensamento nômade não apela para um sujeito universal, não há um conjunto englobante, mas, desenvolve-se em um território sem balizadores, denominado liso.

Para sustentar a característica de via única, a Ciência maior institui ordens e procedimentos, que garantem a continuação de tal caminho, aquilo que foge e escapa dessas estruturas estabelecidas acaba sendo inferiorizado. O Estado precisa de uma mão de obra especializada para o comércio, que faça a economia girar, em virtude disso, apropria-se da Educação para fomentar esse modo de formação.

Portanto, não se considera as Ciências menores como outro saber conforme idealiza teoricamente o conhecimento científico (DELEUZE; GUATTARI, 2012). Elas tangenciam-no, sem pretensões de obter um estado único de verdade, tentando escapar dos métodos e organizações. Não possuem posições duradouras e as incongruências transitam dentre as criações possíveis de serem feitas sem representar um erro ou falha no processo. A hipótese, também do pósestruturalismo, de que a reunião de diferentes áreas do conhecimento potencializa o processo de aprendizagem pode estar presente no movimento CTS. Por conseguinte, o exercício de 
pensamento realizado com o tema nesse escopo teórico pós-estruturalista, torna-o multifacetado, movimentando o território educacional.

Deste modo, pensa-se o conceito de Ciência menor na aposta de possibilitar outros caminhos para a Educação, tal como a prática CTS de Tenreiro-Vieira e Vieira (2005), poderia compor diferentes conhecimentos, mas agregando teoria e prática, tramando os saberes a essa contemporaneidade. Ao invés de oferecer um pensamento aos estudantes, incitá-los a pensar, desapegados de qualquer verdade construída, e que se disseminem diferentes modos de realizarse nos distintos campos sociais pelos quais os sujeitos da Educação circulam.

A aposta é em um pensamento científico que desenvolva a produção de novos sentidos, numa prática também filosófica. Por mais que a Ciência maior traga vantagens, como no caso da produção de etanol, há que se questionar quais são as condições, principalmente econômicas, que conduzem a essa situação. Em suma, a CTS pensada nessa perspectiva se oferece como soma na força de pensar, não somente pelos conceitos estudados, mas também por realçar o pensamento enquanto criação, agregado ao mundo, no afastamento de ideologias e preconceitos, priorizando essas possibilidades nessa contemporaneidade. Assim, os exercícios dessa Ciência menor podem ser atravessados pela imanência, assegurando-se enquanto procedimentos que derivam do vivido e que buscam outras saídas para o que já está pronto, que não buscam respostas e verdades, mas problemas derivados e engendramentos.

\section{Tecnologias do eu}

O estudo dos usos e desenvolvimento da Tecnologia e ensino de CTS é importante para modificar o mundo natural, de acordo com Abreu (2001), e principalmente na necessidade de solucionar problemas. Outrossim, para integrar as diferentes disciplinas e facilitar o aprendizado crítico, tornando-o mais flexível e inter-relacionado, atendendo às demandas do mercado e dos novos modelos de produção. Esse entendimento transita entre os estudos e aplicações da CTS na Educação, porém, aqui, as indagações relativas a essa temática vão além das consequências listadas pelo senso comum: o mau uso dos artefatos tecnológicos, as distrações que a internet pode causar, o distanciamento do convívio pessoal, a falta de infraestrutura e o despreparo dos professores na sua utilização.

Na teoria pós-estruturalista, substrato para essa pesquisa, é solicitada uma pluralidade de sentidos aos conceitos tidos como imutáveis, as apropriações que são realizadas para produzir algo ou fomentar uma força capaz de abalar o já estruturado, movem questionamentos e repostas em áreas tidas como esgotadas. Assim, o entendimento de Tecnologia na qual se quer transitar são os estudos de Michel Foucault (2008), acerca do discurso da biopolítica e do "eu", relacionando-os ao campo educacional.

36 DOI: Em andamento.

R. Bras. de Ensino de C\&T 
Nesta pesquisa, atentam-se as Tecnologias do eu, definida pelo autor, como as práticas que favorecem um modo de relação do sujeito consigo mesmo, que recusa a pressuposta universalidade de um todo, um fundamento a ser seguido. Promovem ações e técnicas sobre o corpo e a alma, articuladas com ideais transcendentes, evita que as relações de poder se cristalizem em estados de dominação. Trata-se de colocar a si próprio como cerne da reflexão, mas alocar-se descolado dos atributos impostos pelo saber moderno, do poder disciplinar e normalizador, de uma determinada forma moral orientada a uma unificação do eu.

De acordo com Foucault (2008) as práticas e Tecnologias do "eu" consistem em: alguns minutos por dia ou por várias semanas e meses ocupar-se de si. Um prazer e lazer operacional: estudar, ler, preparar-se para o que a vida há de oferecer ou até mesmo para a morte, um modo de viver junto aos outros e não individualista. Dispor esse conjunto de práticas e técnicas, de modo que, cada indivíduo produza sua própria vida e gerencie sua liberdade, assim como uma obra de arte é fruto de um artista, a construção da existência de si, seria também uma formação singular.

Nessa relação, a pesquisa de Mundim e Santos (2012) ganha força pois proporciona os estudos dos conceitos CTS tramados à realidade e ao que se passa com os alunos, mais ao nível da subjetividade. Aqui, vincula-se essa prática às Tecnologias do eu, pois os autores atentam para o que se pensa e sente nas atividades propostas, sendo esse movimento fundamental para o cuidado de si, pois coloca os estudantes em contato com suas próprias convicções e pensamentos, operando Tecnologias a favor desses princípios que fortalecem um entendimento desse "eu" e da sua construção enquanto ser social.

No espaço escolar, atualmente, muitos são os momentos em que os alunos se expressam por meio de uma atitude, como o uso das redes sociais ou a ocupação de espaços virtuais, entretanto, poucas vezes atenta-se para essas manifestações de ordem subjetiva, que contaminam os processos de ensino e aprendizagem. É importante buscar, em distintos territórios, modos de constituição com os quais os alunos se identificam nessa contemporaneidade, possibilitando diminuir a distância do educando para com o conteúdo, na relação com a Escola e o professor.

A CTS, neste contexto, pode ser desenvolvida como um processo centrado na pessoa, que valoriza o pensar criativo, inédito, construindo e transformando o modo pelo qual o sujeito faz a experiência de si em relação consigo mesmo. A Educação, conforme Foucault (2012) é uma maneira política de manter ou de modificar a apropriação dos discursos. Assim, é nesse território, envolto em práticas de avaliação, controle e disciplinamento, que as Tecnologias do eu podem ser mais facilmente mapeadas e suas forças reverberadas, tanto as potencialidades do sujeito, como também os modos subjetivos de violência e normalização. 
De fato, a Tecnologia vista como um artefato inovador que envolve um conhecimento técnico e sua aplicação, tal qual um computador, trouxe para a Educação diversos benefícios, inclusive na relação de si com os outros, no ensino e no conhecimento. Entretanto, normalmente, não se aprofundam questões que problematizam as subjetividades dos sujeitos. Atualmente, há muitas imagens disponíveis que povoam o pensamento, com aparências e consumos instantâneos, bem como promessas de receitas para se atingir o saber. A partir desse cuidado de si e da perspectiva CTS, pode-se intensificar as mudanças nessas relações. Conforme os estudos apresentados por Foucault (2008), é preciso conhecer e não renunciar a si mesmo, para não se perder diante dessas ofertas.

A experiência de si, em que o sujeito, sua história e sua constituição como objeto são consideradas inseparáveis das Tecnologias do eu, poderia se tornar catalisadora dessas práticas na Escola. Sendo assim, a Educação CTS pode ser pensada, não somente como um território que se aprende e ensina, mas também vislumbrá-la produzindo formas de experiências de si nas quais os indivíduos podem se tornar sujeitos de um modo particular. Pensa-se em desdobramentos no entendimento acerca da Tecnologia, principalmente, pela Tecnologia do eu, conforme os estudos de Foucault, permeando conceitos e problematizando a temática em uma perspectiva pósestruturalista.

\section{Sociedade disciplinar e de controle}

Discorrendo sobre a Sociedade disciplinar, Foucault (1987) identificou, na segunda metade do século XVIII, o corpo como objeto de poder. O controle sobre ele e em seu modo de vida evitava possíveis levantes e protestos, práticas estas que se mostraram mais eficientes. $\mathrm{Na}$ Sociedade disciplinar trata-se do corpo, em uma repressão que não o deixa escapar dos objetivos impostos, as suas atitudes e sinais são sempre ativos.

O domínio se dá na produção que o corpo irá realizar, a sua importância está no seu vigor, na organização de seus atos. O exercício é colocado em primeiro lugar, operando sobre as energias, de forma constante e sucessiva, focando nos processos de funcionamento mais do que nas consequências. A Sociedade disciplinar produz códigos que examinam e determinam incessantemente o andamento, os territórios e as oscilações que decorrem dos condicionamentos impostos. De acordo com Foucault (1987), as disciplinas são os métodos que permitem o controle minucioso das operações do corpo, a sujeição de suas forças, impondo uma relação de docilidade e utilidade.

O disciplinamento é tanto da ordem individual quanto coletiva. Na Escola, por exemplo, cada sujeito deve desempenhar a sua função, de modo a garantir a formação dos alunos, bem como os demais objetivos inerentes à Educação. Para minimizar as falhas que porventura aconteçam, as instituições se consolidam com mecanismos eficientes, em conjuntos sólidos, de 
tal modo, que se determinada pessoa não for capturada, englobada pelo trabalho, será pela igreja ou pelo saber, tendo como ideal aquele que percorre todo o caminho preconcebido.

Na prática CTS realizada por Andrade e Carvalho (2002), os procedimentos de pesquisa remetem a exercícios disciplinares, como as discussões em pequenos grupos, com temáticas direcionadas pelo professor, que registra e anota qualquer consideração medida como válida para o objetivo do estudo. Além disso, as escritas extraídas dos estudantes eram condicionadas por perguntas prévias e a avaliação dava-se por meio da observação, medindo o envolvimento na proposta, e provas escritas. Esses mecanismos retiram a potência do corpo, torna-o apto a uma determinada finalidade, exercita-o para melhorar o desempenho.

Assim, a Sociedade disciplinar se constitui por meio de práticas, que fabricam indivíduos úteis, permitindo a garantia da submissão das forças e dos corpos. Ainda hoje, na Escola, pode-se ter acesso a essas produções quando se vislumbra a estruturas físicas e espaciais do ambiente, pensadas a partir do modelo do panóptico (FOUCAULT, 1987). O aspecto da arquitetura mostra-se como forma de punição eficaz através da privação da liberdade, bem como o ir e vir, excluindo o sujeito de um determinado grupo social ou separando alunos em turmas, com espaços separados, classificando cada classe.

Entretanto, atualmente encontra-se uma crise generalizada dos meios de confinamento e outro modelo ocupa os espaços deixados, com um controle à distância. $O$ colapso das instituições modernas concebe o surgimento de um novo regime de dominação, denominado, por Deleuze (1992), de Sociedade de controle. Desenvolve-se nos limiares da Modernidade e se desenrola para a Pós-modernidade, em que mecanismos de poder são imanentes ao social, trazendo consigo a premissa de um caráter totalitário e democrático. O corpo ainda é objeto de disciplinamento, mas, além disso, o foco recai sobre as populações e grandes massas de pensamento, com redes flexíveis, flutuantes que colocam a funcionar esses imperativos, tal qual as ações na área da saúde e no espaço da cidade que controlam essa Sociedade.

Na Sociedade de controle há uma rede que classifica, normatiza e sanciona, mas esse status é igualmente temporário. As referências sociais modificam-se constantemente antes mesmo de estabilizar-se; engendram-se novas subjetividades e percepções em que são oferecidos modos de ser e de pensar que só tendem a contribuir para a manutenção do que está posto. Os desejos, assim como se constroem rapidamente, são substituídos por outros, que custam mais, despendem, igualmente, trabalho e dedicação maior, sufocando as escolhas em um ciclo degenerativo, onde as aceitações sociais passam pela dedicação que é dada a esse sistema. É em função disso que "o marketing é agora o instrumento de controle social [...]. O controle é de curto prazo e de rotação rápida, mas também contínuo e ilimitado [...] o homem não é mais confinado, mas o homem endividado" (DELEUZE, 1992, p. 228). 
Artefatos técnico e científicos são postos a funcionar na Sociedade de controle, como é o caso das mídias, com função de distrair, informar, domesticar, massificar e expandir, sem falhas, os imperativos coletivos. Recondicionando, também pela publicidade, diferentes atrativos, dentre eles o consumo e a produção constante de mercadorias, que infringem nas liberdades de escolha e condicionam modos de vida e existência. A globalização é alçada como imprescindível, em que as compras e vendas são sempre da ordem do macro, a excelência está na aquisição de um ideal que serve e abrange as necessidades de todos. A CTS percorre esse caminho ao tratar a própria Tecnologia como uma mercadoria, na qual, para estar no ápice científico, necessita-se trabalhar com o que há de mais avançado tecnologicamente no comércio.

Quem produz o controle nessa Sociedade são as próprias Tecnologias, como câmeras de vigilância, celulares, as Instituições, escolas, agências e a própria população. Cada sujeito que tem internalizado o modo de viver contemporâneo acaba sendo um vigilante de outro, buscando sempre uma normalidade nas ações, baseado em um ideal instituído. Ainda, como uma submissão do homem à máquina, pode-se pensar os drones, pequenos aviões não tripulados que incorporam os conhecimentos mais avançados, objetivando o domínio do espaço aéreo, do jogo bélico e da comunicação, inclusive sendo usado para fazer entregas de encomendas.

A todo o momento estão sendo os sujeitos constituídos, modificados e tornados contemporâneos. Habita-se a era da transformação, da informação, das mídias da indústria digital e do consumo. Um tempo que refaz um mundo a todo instante, em que a cultura se sobrepõe a todas as fronteiras. A CTS contribui para que a Sociedade, bem como a Educação, tenha impregnada em sua estrutura linhas de forças e verdades que sustentam modos de ser padronizados. A Educação CTS pode pensar essas implicações com relação aos sujeitos, e como eles se constituem, com o meio em que vive, atravessados por modelos de vida, padrões econômicos e sociais.

\section{Considerações Finais}

Os estudos dos conceitos de Ciência e Tecnologia contribuem para que a Sociedade e a Educação tenham impregnadas verdades que sustentam modos de ser em suas estruturas. A CTS pode conceber um ensino que crie estratégias de existências em meio a um conjunto de possibilidades mutantes, como o que está disposto no contemporâneo.

Atualmente, há diversos modos de pensar a Educação, mesmo que as Ciências maiores e menores apareçam ao mesmo tempo nesse território, em que são postas a funcionar práticas disciplinares na Sociedade de controle percebe-se a importância de fugir do mesmo, do totalizante, do unitário. Outrossim, reinventando novas maneiras de se relacionar enquanto seres sociais, em um tempo que se necessita de revoluções políticas e culturais, para que a vida esteja menos perturbada, na esteira da teoria pós-estruturalista. 
A Educação CTS contribui para uma prática que vai além das questões discorridas tradicionalmente nas pesquisas educacionais, uma Tecnologia considerando o "eu", uma Ciência menor, inserida na ética e estética da existência, imanência, multiplicidade, no singular, procurando movimentar o pensamento diante das resistências em que se é experimentado. Sendo possível ter formas outras de ser e viver na contemporaneidade, capaz de minimizar as mazelas vividas neste cenário.

\section{Referências}

ABREU, R. G. de. Tecnologia e ensino de ciências: recontextualização no novo ensino médio. In: Encontro nacional de pesquisa e educação em ciências, Atibaia: Abrapec, 2001.

ANDRADE, E. C. P. de; CARVALHO, L. M. de. O proálcool e algumas relações CTS concebidas por alunos de 6ạ série do ensino fundamental. Ciência e Educação, v. 8, n. 2, p. 167-185, 2002.

BAUMAN, Z. O medo líquido. Rio de Janeiro: Jorge Zahar, 2008.

DELEUZE, G. Post-scriptum sobre as sociedades de controle. In: Conversações. Rio de Janeiro: Editora 34, p. 223-230, 1992.

DELEUZE, G.; GUATTARI, F. Mil Platôs: capitalismo e esquizofrenia. Vol. 5. 2. ed. São Paulo: Editora $34,2012$.

FOUCAULT, M. Vigiar e punir: nascimento das prisões. Petrópolis, RJ: Vozes, 1987.

FOUCAULT, M. A hermenêutica do sujeito. 2. ed. São Paulo: Martins Fontes, 2006.

FOUCAULT, M. A ordem do discurso. 22. ed. São Paulo: Edições Loyola, 2012.

FOUCAULT, M. Tecnologías del yo. Buenos Aires: Paidó, 2008.

FREIRE, P. Educação como prática da liberdade. Rio de Janeiro: Paz e Terra, 1967.

LINSINGEN, I. V. Perspectiva educacional CTS: aspectos de um campo em consolidação na América Latina. Ciência \& Ensino, v. 1, 2007.

MUNDIM, J. V.; SANTOS, W. L. P. dos. Ensino de ciências no ensino fundamental por meio de temas sociocientíficos: análise de uma prática pedagógica com vista à superação do ensino disciplinar. Ciência e educação, v. 18, n. 4, p. 787-802, 2012.

SILVA, T. T. da. O adeus às metanarrativas educacionais. In: T. T. da Silva (Org.), Identidades terminais. Petrópolis, RJ: Vozes, p. 236-250, 1996.

TENREIRO-VIEIRA, C.; VIEIRA, R. M. Construção de práticas didático-pedagógicas com orientação CTS: impacto de um programa de formação continuada de professores de ciências do ensino básico. Ciência e educação, v. 11, n. 2, p. 191-211, 2005.

DOI: Em andamento. 
Msc. Samuel Molina Schnorr - Universidade Federal de Pelotas, Programa de Pós-Graduação em Educação, e-mail: schnorr m@yahoo.com.br

Dra. Carla Gonçalves Rodrigues - Universidade Federal de Pelotas, Programa de Pós-Graduação em Educação, e-mail: cgrm@ufpel.edu.br 